\title{
Self-Awareness and Personal Growth: Theory and Application of Bloom's Taxonomy
}

\author{
Hasan UGUR ${ }^{*}$ \\ Petru-Madalin CONSTANTINESCU* \\ Michael J. STEVENS***
}

\section{Suggested Citation:}

Ugur, H., Constantinescu, P.M., \& Stevens, M.J. (2015). Self-awareness and personal growth: Theory and application of Bloom's Taxonomy. Eurasian Journal of Educational Research, 60, 89-110

Doi: 10.14689 /ejer.2015.60.6

\begin{abstract}
Problem Statement: In this article, we summarize a group-based, selfdevelopment curriculum based on humanistic principles, framed by contemporary self-determination theory (SDT), and designed in accordance with Bloom's Taxonomy. The processes of awareness and integration are common to SDT and Bloom's Taxonomy, and to our knowledge, have not been applied together with the practical goal of promoting the student self-development in an educational setting.
\end{abstract}

Purpose of the Study: The underlying assumptions of our curriculum hold that (1) the self functions as the psychological agent responsible for regulating personal behavior, and that (2) personal growth is an outcome of the motivation to fulfill intrinsic goals coupled with the integration of learning through an awareness of personal limitations and potentialities. We describe the design and implementation of a school-based curriculum that integrates core elements of SDT with the sequential levels of cognitive and affective learning articulated by Bloom's Taxonomy and that is intended to facilitate the student self-development.

Method: Three distinct theoretical and empirical ingredients of SDT form the basis of our curriculum: goals and values, organismic integration, and mindful action. These core components of SDT are rooted in the humanistic tradition but can be transformed into a sequence of practical learning goals and activities when viewed through the lens of Bloom's

*Corresponding author: Dr. Hasan Ugur, Fatih University, hugur@fatih.edu.tr

${ }^{*}$ Lucian Blaga University, petru@psiho-helpline.ro

***tProf. Dr. The Chicago School of Professional Psychology,

michaelstevens@thechicagoschool.edu 
Taxonomy. We demonstrate how Bloom's Taxonomy provides the architecture needed to implement the elements of SDT in such a way that students are able to engage in a programmatic process of selfdevelopment. In other words, the levels of Bloom Taxonomy are used to structure the application of the broad SDT/humanistic principles on which personal growth is founded.

Findings: Combined with the anecdotal reactions of group members and facilitators, our impressions suggest that the consistent expression of personally selected values and characteristics requires that these aspects first become internalized as meaningful guides for living, second, motivate behavior that is consistent with the chosen values and characteristics, and third, contribute to a sense of well-being and personal growth.

Conclusion and Recommendations: The process of self-development can be facilitated by the internalization of cognitive learning and is supported by affective processes that, together, yield favorable developmental outcomes for students. Although we did not subject our group-based curriculum to rigorous empirical evaluation, we encourage efforts to establish its effectiveness through qualitative and quantitative research.

Keywords: Self-awareness, motivation, personal growth, Bloom's Taxonomy

\section{Introduction}

Self-awareness is not only a gift, but it is a responsibility.

Mufti James Hannush

Many years have passed since existential-humanistic ideas were developed and empirically tested by research on Self-Determination Theory (SDT). Bloom's Taxonomy (Bloom, 1956; Bloom, Engelhart, Furst, Hill, \& Krathwohl, 1956), an important contribution to the development of school curricula, has also been widely used for some time. However, these seemingly different theoretical and empirical traditions have seldom been linked, despite the fact that their conceptual frameworks are complementary. In this article, we summarize an innovative curricular program based on SDT principles, which in our view is a modern relaunching of the existential-humanistic paradigm, and Bloom's Taxonomy, which has an applied focus on improving curriculum design and learning outcomes. There are no research studies that have examined our synthesis and application of SDT and Bloom's Taxonomy. However, from the theoretical and empirical literature (e.g., Bloom, 1956; Bloom et al., 1956; Krathwohl, 2002; Ryan, Huta, \& Deci, 2008; Seligman \& Csikszentmihalyi, 2000), it is possible to find indirect support for our applied synthesis. For example, one important bridge between the different conceptual and research traditions of SDT and Bloom's Taxonomy is that the more values and knowledge become integrated into the self, the more likely that academic motivation is enhanced and learning outcomes improve. Our innovative curriculum program has both scientific and applied value in that it allows researchers and practitioners 
access to a complex yet efficient program, which calls for a new line of research to empirically test the education-related effects of melding SDT with Bloom's Taxonomy. The program is consistent with the idea that flourishing should be regarded as an ideal aim of education (Wolbert, de Ruyter, \& Schinkel, 2015).

\section{Humanistic Psychology and Self-determination Theory}

The various conceptual models within traditional humanistic psychology share a central tenet: the fundamental value of the actualization of human potential. Both Abraham Maslow and Carl Rogers (Maslow, 1968; Rogers, 1961) developed optimistic theories that underscore the capacities, opportunities, and innate trajectory of human beings toward personal growth and psychological well-being. Selfdetermination theory (SDT), developed more recently, has refined and advanced the optimistic perspective of traditional humanistic psychology by placing importance on the centrality of the self as a causal agent in human functioning. It stands in sharp contrast with deterministic and reductionist paradigms favored by contemporary psychological science, such as applied behavior analysis and cognitive neuroscience (Sheldon, Joiner, Pettit, \& Williams, 2003). However, research has shown that a positive life orientation in the absence of tangible accomplishment is linked to negative psychological, interpersonal, and real-world outcomes. This paradox has been described in the literature as the tendency in contemporary society to emphasize positive illusions. Positive illusions appear to make life more satisfying in the short term, but in fact lead to negative consequences in the long run (Schneider, 2011). For example, the emphasis on cultivating self-esteem in students in educational settings, which originated with the broader self-esteem movement (Baumeister, Campbell, Krueger, \& Vohs, 2003) must be accompanied by real academic growth grounded in real academic achievement for psychologically beneficial outcomes to unfold. Of course, positive illusions can produce a sense of well-being in educational settings, but as Viktor Frankl (1969) noted, genuine and lasting well-being is the result of a "life well-lived". Thus, without real accomplishments there can be no eudaimonic well-being (Ryan \& Deci, 2001).

Ryan and Deci (2001) made a clear distinction between what is called hedonic well-being and eudaimonic well-being. Hedonic well-being centers on pleasurable life experiences, with the accumulation of such experiences leading to greater overall personal happiness. The eudaimonic tradition in contrast emphasizes living life well, that is, making choices that are congruent with authentic being. These choices have been posited to facilitate the development and expression of individual potentialities, which in turn contribute to a sense of subjective well-being. Though related, eudaimonic well-being can be viewed as more profound and enduring than hedonic well-being. For example, Schueller and Seligman (2010) compared the pursuit of pleasure, meaning, and engagement and concluded that the latter two goals, which are considered eudaimonic, are stronger predictors of long-term psychological wellbeing. Waterman (2008) echoes this view, suggesting that the actualizing of potentialities can be more beneficial in the long-term than the accumulation of pleasurable life experiences. We should note that the traditional humanistic proposition that accurate perceptions of reality are a precondition for well-being and 
personal growth (Jahoda, 1953; Maslow, 1950) has been contradicted by more recent research. According to these studies, positive illusions represent healthy defense mechanisms (e.g., Taylor \& Brown, 1988), whereas depressive realism (e.g., Alloy \& Abramson, 1979) can prove detrimental if left unchallenged (Robins \& Beer, 2001).

Positive psychology, while a modern extension of humanistic psychology with a strong empirical foundation, has tended not to focus on issues of positive illusion versus realistic experience and actual accomplishment (Schneider, 2011). As stated above, personal growth has been central to the perspectives set forth by Maslow and Rogers (Maslow, 1968; Rogers, 1961) and, in a way, has been discovered anew with similarly conceptualized SDT as 'normal' striving by the individual toward wellbeing, joy, creativity, and accomplishment. SDT is considered part of the broader positive psychology movement and has led to significant advances by demonstrating that intrinsic motivation, well-being, and adaptive functioning are enhanced by the pursuit and eventual attainment of available and personally meaningful life goals, or aspirations (Deci \& Ryan, 2000). Part of this assertion reflects common ground between SDT and social cognitive theory. Social cognitive theories (e.g., Bandura, 1997; Shoda, Wilson, Whitsett, Lee-Dussud, \& Zayas, 2015) contend that what is required for well-being to occur is a process whereby individuals aspire to wellbeing, in other words experiencing oneself as capable of attaining personal aspirations and then attaining them, at least in part. The point of departure between social cognitive theory and SDT is that SDT maintains that self-efficacy and partial goal attainment is not enough to experience well-being; rather the content of aspiredto goals is critical (i.e., intrinsic vs. extrinsic) (see Deci \& Ryan, 2000 for a full discussion). A key life goal is the aspiration for personal growth, the pursuit and attainment of which has been shown in numerous studies across many cultures to contribute to well-being and adaptive functioning.

Research on personal aspirations within SDT began in 1993 when Tim Kasser and Richard Ryan (1993) published their controversial article, "A Dark Side of the American Dream: Correlates of Financial Success as a Central Life Aspiration." Since then, other studies have replicated entirely or in part the claims that the pursuit of reasonably attainable intrinsic goals and/or the achievement of at least some of these goals (i.e., personal growth) enhances the experience of well-being. The relationship between intrinsic motivation and well-being has been demonstrated cross-nationally in research conducted in the United States, Russia, Romania, and Germany (Frost \& Frost, 2000; Ryan, Chirkov, Little, Sheldon, Timoshina, \& Deci, 1999; Schmuck, Kasser, \& Ryan, 2000). Stevens, Constantinescu, and Butucescu (2011) found that personal growth is related to well-being in both US and Romanian students, citizens of two countries with very different cultures and histories.

\section{Personal Growth and Subjective Well-being in Educational Settings}

There are many examples from theory and research concerning the importance of students' goals for their academic achievement, well-being, and personal growth (Kiaci \& Reico, 2014; Vansteenkiste, Lens, \& Deci, 2006; White \& Murray, 2015; Wolbert et al., 2015). The theoretical and empirical literature underscores the longterm benefits of striving for and achieving personal growth in tangible ways. Other 
studies conducted in school settings have also shown that aspiring to personal growth leads to a variety of desirable outcomes. For example, Bauer and McAdams (2004) and Bauer, Park, Montoya, and Wayment (2015) found that university students with personal, growth-oriented goals displayed higher levels of social and emotional well-being, as well as social and cognitive maturity. Tuominen-Soini, Salmela-Aro, and Niemivirta (2008) found that university students who were oriented toward personal growth (i.e., reflective and experimental growth motivation) scored high on measures of maturity and well-being. These findings have important implications for the design of curricular programs geared toward student psychological development.

Bloom's Taxonomy was developed out of a need to standardize different aspects of education, such as learning objectives, the curriculum, and evaluative measures (Bloom, 1956; Bloom et al., 1956). Although the taxonomy went unnoticed at first, its popularity grew, and it has since been translated into many different languages (Krathwohl, 2002). The taxonomy has a central cognitive domain that specifies a framework in which distinctive cognitive learning activities are identified for each of the six sequential stages through which the acquisition of knowledge and skills takes place. The six stages of learning that comprise the cognitive domain of the taxonomy are: Knowledge, Comprehension, Application, Analysis, Synthesis, and Evaluation. Although these stages were further subdivided in the original taxonomy (Bloom et al., 1956), their description goes beyond the scope of our article. The revision undertaken by Kratwohl (2002) relabeled several of the stages and transformed the taxonomy into a bi-dimensional structure that accommodates both knowledge and cognitive processes. Notwithstanding revisions to the original taxonomy (Krathwohl, 2002), its fundamental ideas have for the most part been preserved, and it continues to be used by teachers in the design of course content and learning activities.

In addition, a distinctive affective domain was integrated into the original taxonomy. This affective domain has five levels: Receiving, Responding, Valuing, Organizing, and Characterization. Profound learning takes place when the student is able to assign a specific value to the content of what is being learned and then integrate that learning into his or her personal system of experience and values (Allen \& Friedman, 2010). The affective domain of Bloom's Taxonomy resonates with the tenets of humanistic psychology as well as with the propositions that undergird SDT; that is, intrapersonal congruence in values is seen as indispensible to the motivation to pursue meaningful activity and to the experience of well-being and personal growth (e.g., Deci \& Ryan, 2000; Rogers, 1964). As already stipulated, intrinsic motivation and well-being are necessary for quality of life (i.e., "living well"). Extrapolating to educational settings, information imparted by instructors should ideally be integrated into the personal worldview of students, which consists of experiential knowledge and values needed to achieve a rewarding learning experience and a psychological transformation in perspective. Transformative learning occurs when certain conditions in educational settings are met such that the worldview of the student is expanded and deepened through the process of learning that intentionally seeks to integrate new information into the student's experiential history and value system (for a detailed discussion of learning and values, see Deci \& 
Ryan, 2000; Rogers, 1964; Wolbert et al., 2015). The cognitive-affective transformation just described can have lasting benefits for students, educational institutions, and society as a whole.

Thus, Bloom's Taxonomy can be applied as a framework for personal growth because it appears to overlap with two of the five mini-theories associated with SDT (Vansteenkiste, Niemiec, \& Soenens, 2010). These mini-theories are a group of narrower theories born of inductive-deductive research that constitutes the larger motivational theory of SDT as well as other related conceptual models, some of which obtain from earlier work in humanistic psychology. These overlapping perspectives include: Organismic Integration Theory (OIT) and Goal Contents Theory (GCT). OIT holds that extrinsic motivation, as well as the cognitive and affective content and processes associated with it, contribute to personal growth when extrinsic goals become internalized and serve to promote the realization of an individual's authentic self via a gentic choices. For extrinsic motivation that has value for personal growth to become internalized and integrated with self-regulated behavior, certain conditions must exist, conditions that offer opportunities to satisfy basic needs, which in our case revolve around hospitable educational environments. GCT, on the other hand, emphasizes goal content as important in determining how someone strives to attain a goal. GCT holds that both the aspirational content (i.e., goals) and the manner in which such goals are pursued are dimensions of motivation that contribute to well-being and psychological functioning (see Deci \& Ryan, 2000; Kiaci \& Reico, 2014). Personal growth (i.e., intrinsic aspiration) is viewed as a fundamentally worthwhile aspiration to pursue, with well-being and psychological health stemming from the inherently positive consequences of attaining some measure of personal growth.

In the following section, we delineate how Bloom's Taxonomy can be conceptually tied to humanistic psychology's core propositions about the conditions required for self-awareness and psychological growth. We then present how learning activities derived from this theoretical integration can be designed to enhance selfawareness and personal growth in students.

\section{Using Bloom's Taxonomy to Enhance Personal Growth in Educational Settings}

Our proposed group-based curriculum to enhance self-awareness and personal growth in students reflects both OIT as well as GCT mini-theories. Namely, the group curriculum provides the facilitative conditions within which academic content can be internalized and prompts students to construe and experience the curriculum not merely as classroom learning, but rather as offering the promise of personal growth, which is an intrinsic goal of SDT. In addition, mindfulness research within an SDT framework (e.g., see Brown, Ryan, \& Creswell, 2007) has shown that conscious awareness of deeply held values, coupled with living in accordance with these same values, is a formula for enhancing authenticity and eudaimonic wellbeing, which are historically humanistic aspirations (Rogers, 1961). Our group curriculum is intended to encourage and support students to become more conscious of their own values and to live by their values so as to achieve greater eudaimonic well-being (e.g., Bauer \& McAdams, 2004; Bauer et al., 2015; Kiaci \& Reico, 2014; 
Ryan et al., 2008). As stated at the outset, one of our main propositions is that, as long as the individual aspires to personal growth and pursues this aspiration vis-àvis tangible, real-world outcomes, this expression of intrinsic motivation, along with purposive and meaningful forms of extrinsic motivation (Stevens et al., 2011; Stevens, Constantinescu, Ugur, \& Constantinescu, 2015), are likely to contribute both to momentary and to enduring adaptive functioning and well-being (White \& Murray, 2015; Wolbert et al., 2015), provided that conditions permit the fulfillment of basic needs. At Fatih University in Istanbul, Turkey, we developed a group-based curriculum to facilitate the personal growth of students. The curriculum adopts Bloom's Taxonomy (Bloom, 1956; Bloom et al., 1956; Krathwohl, 2002) as a model for enhancing learning, self-awareness, and well-being.

Instead of using Bloom's Taxonomy in the traditional way to assist the curriculum designer and classroom instructor (Krathwohl \& Anderson, 2010), we drew on the taxonomy to develop a group-based program intended to promote individualized pathways to self-development. We believe that Bloom's Taxonomy can facilitate personal growth by activating students' intrinsic motivation and extrinsic motives that serve higher-order needs, increasing awareness of their real potentialities, and focusing attention on their behavioral choices. We further believe that by being connected psychologically to their personal qualities, students will seek opportunities for personal growth both in the classroom and in non-educational settings (Newman, 2000). In short, Bloom's Taxonomy, with its developmental levels and applications to learning, provides an ideal framework with which to implement the goal of positive psychology to build strengths in students (Seligman \& Csikszentmihalyi, 2000; Wolbert et al., 2015).

\section{Method}

\section{Participants}

Seventy counseling psychology undergraduates who had basic coursework in group counseling, along with seminars on cognitive and emotional development, positive psychology, social comparison theory, and peer relations were invited to participate voluntarily in pilot groups led by master's-degree facilitators. Participants applied online to participate in a group study. There was a rule for inclusion as a member of the group study. The participants were required to see graphs with the results of self and classmates' evaluations on some chosen personal characteristics. The students then clicked on a characteristic that determined what group they would be enrolled in. Students, who didn't see their own graphs, were not accepted. To be considered, the graph had to have the evaluations of at least ten classmates. Each group had 8-12 students. Group facilitators were graduated master's students in the counseling or psychology departments, so they had group study experience (during undergraduate and master's levels). They all volunteered to be supervisors, and they received an online certificate from Akademik Pencere by the end of the program. Additionally, before starting applications, the first author offered them seminars in positive psychology and social comparison theory and 
granted them the right to use the online group studies. The supervisors also had experience in leading seminars on positive psychology and social comparison theory and their applications.

Procedure and Results

Our group-based curriculum was first launched as a part of a master's-level course but evolved into noncredit volunteer opportunities for master's-degree students and undergraduates. The number of students in any group was restricted to between 8 and 12 in order to ensure adequate individualized attention. Each group met weekly for 10 weeks, with each session requiring 45-50 minutes of class time, and built upon the learning activities and outcomes of the previous session. Some of the particularly important levels of Bloom's Taxonomy (e.g., knowledge, analysis, and synthesis) required at least two sessions to complete, depending on the group facilitator and level of student participation.

Roles and Responsibilities of the Group Facilitator

Each group facilitator had either a postgraduate certificate in group counseling or master's-level coursework and training in group counseling through the Department of Counseling at Fatih University. The yearlong training of group facilitators was carried out by the first author, who developed the group-based curriculum over the course of 15 years of academic and practical work in school counseling. Prior to leading the groups, 31 master's-degree students received academic preparation in the basic principles of cognitive and emotional development, positive psychology, social comparison theory, and peer relations, all of which were presented and extensively discussed in their group counseling course in the school psychology program. As for their orientation and understanding of Bloom's Taxonomy, all group facilitators received (1) an explanation of how the group-based curriculum was derived from and reflected the cognitive and affective domains of the taxonomy; (2) an opportunity to discuss the learning goals associated with each level of the taxonomy, as well as how they could use their knowledge of cognitive and emotional development, positive psychology, social comparison theory, and peer relations in generating learning activities to facilitate learning goals; (3) instruction on how to identify and apply specific learning activities that are matched to the parameters of specific learning goals at each level of the taxonomy; (4) supervised role-plays that permitted guided practice in facilitating different learning goals through the application of relevant learning activities; and (5) feedback from the trainer and other group facilitators on how the content and format of the curriculum, as demonstrated in the role-plays, realized the cognitive and affective domains of Bloom's Taxonomy. After one year of didactic and supervised experiential training, the first author determined that the group facilitators were adequately prepared to carry out the curriculum. Students who comprised the actual groups were recruited from schools in which the master's-degree facilitators were interning. Once the actual groups were formed and before the learning activities began, the group facilitator introduced students to each other with some "ice-breaker" exercises and informed the group about the ethical guidelines and practical procedures to which they were asked to give consent. The group facilitator strove to engage students respectfully and with 
appreciation and encouragement. Specifically, the group facilitator worked to create an atmosphere in which students felt comfortable about being genuine in their selfdisclosures and interactions. In each session, the group facilitator emphasized that each human being is endowed with different characteristics and potentialities and thus will experience the world and function within it differently. Therefore, students came to understand that it is normative for there to be a broad spectrum of personal strengths and limitations revealed in group sessions. Emphasis was placed on becoming aware of the salient values and characteristics that each student possesses as a unique individual because recognition of one's strengths and limitations is the springboard for personal growth and well-being.

Curriculum Focus on Values and Characteristics

Later in the group work, each student selected at least one value or characteristic with the goal of living it more fully and, ultimately, of embodying it. Values such as fairness, helpfulness, respect, responsibility, and truthfulness had been previously identified in the literature as universal (e.g., Kidder, 1994a, 1994b; Kinnier, Kernes, \& Dautheribes, 2000; Schwartz, 2006). Other specific values or characteristics that have no claim to universality include achievement, inquisitiveness, hard work, and patience. These were extracted from interviews with teachers and the parents of the students about the values or characteristics they follow and/or wish to inculcate in their students and children, respectively. In this regard, our approach was both nomothetic and idiographic. The values or characteristics that students choose to focus on in group sessions were either universal or personally meaningful and are featured in the examples provided below. Students selected many different values or characteristics to pursue, with some chosen more often than others. For example, confidence in social relationships, openness about sharing feelings, quality of parentchild relationships, and problem-solving competency were frequently selected values and characteristics. Heterogeneity in the values or characteristics chosen by students has advantages since students not only contribute to the recognition and development of these aspects in themselves and others but are also personally enriched by their exposure to diversity.

\section{Levels and Applications of Bloom's Taxonomy}

Although the group-based curriculum is structured for convenience according to the six sequential learning goals that comprise the cognitive domain of Bloom's Taxonomy, the content of that learning and the learning activities designed to attain it are both cognitive and affective in form. For each of the six levels, there are different learning activities and outcomes that support the goal of enhancing selfawareness and personal growth. However, while always suited to the learning objectives of each level of Bloom's Taxonomy, specific learning activities were allowed to differ among our groups because of a particular group facilitator's capabilities and stylistic preferences and because of the varying dynamics of each group's members. According to Seligman (2007), coaching in positive psychology is a practice without limits to its scope, but it is delimited with regard to interventions. With this issue in mind, we initially approached the development of the groupbased curriculum from a nomothetic point of view, incorporating substantive 
elements from the cognitive affective domains of Bloom's Taxonomy. The curriculum evolved into having a significantly idiographic process component because of the need to tailor learning activities to the distinctive composition and affective dynamics of each group. Thus, our curriculum blended the nomothetic perspective favored by SDT and cognitive psychology with idiographic methods preferred by traditional humanistic psychology.

Knowledge

Learning goal: The goal of the knowledge level is to motivate students to reflect on the values/characteristics they selected by having them generate questions about their chosen value/characteristic. We believe that students at this level can learn to reflect on a specific value/characteristic, examine it from different perspectives, and develop specific personalized knowledge that they can then apply to their selfdevelopment.

Learning activity: The knowledge level is critical to the activation of intrinsic motivation. Students are usually given two weeks to complete this learning activity, which is sufficient time to reflect on their chosen value/characteristic and interact with other group members. The group facilitator explains the goal of the knowledge level and begins the learning activity by asking why students selected the values/characteristics that they did. After giving students time to respond, they are asked to write on a sheet of paper as many questions as they can about their chosen value/characteristic. The group facilitator informs them that a "famous master" will answer their questions at the next group session. One week later, the group facilitator tells students that each of them is in fact a famous master capable of answering the questions themselves, either individually or collectively.

In one group session, for example, students selected five different values/characteristics: being patient, successful, hardworking, helpful, and curious. Students prepared as many questions as possible for the following session. When the group next met, three students who selected the same value/characteristic hardworking - read their prepared questions: "What does hardworking mean?, " "Why do people call others lazy?" and "Is doing homework enough to be a hard worker?" All of the students discovered that there were many more questions that they could generate for the value/characteristic of hardworking. As a result, other group members added questions (e.g., "Who are the hardest workers in the world?," "Is Bill Gates a hard worker?," "How can a musician be a hard worker?"). Prepared and new questions were met with applause, which appeared not only to motivate students who prepared questions, but also those who spontaneously contributed their own questions.

Comprehension

Learning goal: There are two goals associated with the comprehension level. The first is to gather information about the selected values/characteristics and motivate students to examine them by noting the questions and answers that group members offered in the previous session (i.e., knowledge level). The second is to demonstrate that others can construct and experience alternative personal realities, leading 
students to examine more critically their own and other values/characteristics. The overarching aim of this level is to facilitate a perspectival understanding and appreciation of the values/characteristics, that is, to promote metacognitive awareness and cognitive-affective development (Kiaci \& Reico, 2014; Williams \& Blythe, 2002) as well as internalization of that awareness (Schunk, 1999).

Learning activity: At this level, students who have been identified as "famous masters" of particular values/characteristics attempt to answer questions about these aspects posed by other group members. The group facilitator asks students to attend closely to each question and answer, encouraging them to respond to any value/characteristic they wish in order to enrich the conversation. For some group members, this process can promote beneficial secondary outcomes, such as comfort and confidence in participating in groups, which is tied to well-being (Berndt, 1999; Wentzel \& Wigfield, 2007). If there are important perspectives that have not been identified by students, the group facilitator can prompt additional contributions by using reflective communication skills. Such interventions not only increase the activity level in the group but also serve to summarize and review the output of the knowledge level just completed. Obviously, generating interest and engagement in students is critical given the powerful influence of peers on cognitive and emotional development. Students who select a particular value/characteristic also have the opportunity to learn about some they did not choose, perhaps ones that they will reflect upon in terms of their personal strengths and limitations. Such indirect learning can raise self-awareness and stimulate personal growth. Taking advantage of peer culture as it emerges in group sessions is integral to the learning that takes place at all levels of our taxonomy-based curriculum. In this sense, the process of peer learning provides a means by which to socialize students' motivation, engagement, and attainment (Ryan \& Deci, 2000; White, \& Murray, 2015).

\section{Application}

Learning goal. The goal of the application level is to focus the attention of students on past actions that reflect their chosen value/characteristic and on what they believe they need to do to behave on a daily basis in ways that are more congruent with salient values/characteristics.

Learning activity: After developing a variety of perspectives on values/characteristics through the learning activities conducted in the knowledge and comprehension levels, students are invited to turn their attention to their own behavior, specifically what they did last week. The group facilitator briefly discusses the importance of how each group member puts their selected value/characteristic into daily practice. As a learning activity, students shut their eyes for 2-3 minutes and reflect on what they did during the past week that exhibits their chosen value/characteristic. Students are instructed to reflect on the positive and/or negative events that followed from their actions or inaction. Students are then asked to share their remembered experiences. The purpose of sharing this information is to raise awareness of and motivate appraisal of the degree to which behavior is congruent with previously identified values/characteristics. Students do not appraise their actions while disclosing them, but, as a consequence of making explicit 
how they expressed or did not express their chosen value/characteristic, they begin to recognize and evaluate their actions. To be clear, this learning activity is framed as an exercise to heighten the self-awareness of potentialities rather than to find fault. While the group facilitator encourages participation, he or she respects the right of any student not to participate; in such cases, the facilitator relies on the supportive and non-demanding peer culture that has become the group norm to subtly induce participation.

As a continuation of the learning activity for this level, the facilitator invites students to focus their attention on themselves rather than on others. Students who selected a particular value/characteristic are asked to position themselves at a particular point along a line that represents the extent to which they enacted that value/characteristic during the past week. Students have an opportunity to change where they stand if they wish. A line is drawn on the floor at the front of class with numbers printed alongside the line that represent percentages. Each student approaches the line and decides where he or she will stand, explaining to the group why he or she stood next to a particular numerical value. For example, if a student, whose chosen value/characteristic is "hardworking," stands at the number 50, this decision means that he or she estimates having exhibited hardworking behavior on half of the occasions when such behavior was possible. For the most part, students in our groups stood next to percentages that ranged from $40 \%$ to $70 \%$. When asked why they chose to stand where they did, many reported that they did not believe they were especially capable or consistent in performing their selected value/characteristic. Some illustrative reasons that students gave for their low-tomoderate level enactment of values/characteristics were: "I am not good at working hard ... ; it's the way I am;" "I am not good at being patient because I get angry very quickly;" and "I am not helpful to my classmates because sometimes I am not as good as I could be." These examples show how processing the line exercise can enhance awareness of personal limitations.

Students are also asked to identify barriers that prevent them from positioning themselves where ideally they would like to stand. Interestingly, most students were unable to identify any barriers, though some mentioned their parents and teachers. A few students positioned themselves at the number 100. They reported having performed their selected value/characteristic whenever possible and felt very positive as a result. To motivate such students to improve the consistency between their preferred value/characteristic and action (even though they did not perceive a need for improvement), they were asked to identify another student who represents the embodiment of the value/characteristic in question. The outcome of this social comparison to an idealized representative of the selected value/characteristic is a more realistic appraisal of how closely the student's actions match the value/characteristic.

Once this learning activity is completed, the group facilitator explains the importance of personal agency in the lives of students, how personal agency can be harnessed, and the importance of challenging internal and external barriers that prevent the expression of personal agency (Fox \& Riconscente, 2008). In the 
discussion that follows, the group facilitator refers back to the knowledge and comprehension levels of Bloom's Taxonomy, in which students pose and answer questions. The group facilitator reminds students to monitor how closely their actions match their selected value/characteristic in preparation for the next session. The following week, students share their experiences of what they did between sessions. Typically, some students report that they remembered the learning activities of earlier sessions as they encountered new situations and, as a result, strove for greater self-awareness and congruence. If students communicate an aspiration to behave in ways that are more consistent with their chosen value/characteristic, it is not unreasonable to infer that intrinsic motivation is aroused. Realistically, we do not expect students to achieve substantial personal growth in a few weeks; however, we do expect that this learning process will sustain increased self-awareness and personal growth over time. We also believe that it is important not only to support students but also to serve as role models so that they become more inclined to realize salient values/characteristics. We wish to emphasize that students exert personal agency in their decision to apply or not apply what they have learned based on their subjective evaluation of how well this learning fits with their experience and how they want to live their lives.

\section{Analysis}

Learning goal: The goal of the analysis level is to induce students to examine the motives for enacting the chosen values/characteristics, why they were enacted or not enacted, and how the values/characteristics might be expressed in more consistent and meaningful ways. Each student's expression of a chosen value/characteristic is processed in the group from the perspective of positive psychology; that is, we wanted students to become more aware of personally meaningful action and, thus, more consciously self-regulated, as has been advocated by research on mindfulness within an SDT framework (see Brown et al., 2007).

Learning activity: Each student selects one or two behaviors related to their chosen value/characteristic, share his or her thoughts and feelings about the circumstances and motivations for the behaviors, appraises the degree to which a chosen value/characteristic was performed, and generates suggestions to realize greater consistency in the expression of meaningful action. By engaging their distinctive cognitive and affective perspectives, students are assisted in understanding and appreciating how their personal growth is an outcome of personal agency (Fox \& Riconscente, 2008). The significance of personal agency is highlighted via the lived experiences shared by students and by the group facilitator, who processes this material and moderates a discussion of the role of personal agency in managing action that contributes to well-being (Fox \& Riconscente, 2008; Kiaci \& Reico, 2014). Using the "line exercise" first introduced in the application level, students indicate where at this moment they would position themselves based upon the actual (vs. desired) expression of their chosen value/characteristic. The line exercise is intended to raise awareness of any change in the consistent expression of values/characteristics as well as the influence of personal agency on intrinsic motivation and well-being. Although it is not essential for students to carry out 
personally desired behavior, the enactment of the chosen values/characteristics is likely to bolster intrinsic motivation for self-awareness and personal growth while the group meets and to sustain intrinsic motivation after the group has ended (Pintrich \& de Groot, 1990; Schunk, 1999; Wolters, 2003).

The group facilitator attempts to motivate students who are less inclined to enact their chosen values/characteristics by encouraging them to consider how they might narrow the gap between their performance goals and actions. If properly reframed, students are able to experience disappointments or setbacks as motivational opportunities for greater self-awareness and personal growth. Thus, students are asked to describe how they would act if they were to encounter the same situation in the future. They imagine alternative responses to those situations and how they would appraise the consistency of their actions with their chosen values/characteristics. This learning activity has promise to motivate students not only to become more aware of their actions but also to move them to acquire or improve the competencies needed for self-regulation. Peer support for this exercise is invaluable in freeing students to take risks with minimal concern about losing selfesteem.

\section{Synthesis}

Learning goal: The goal for the synthesis level is to motivate students to draw upon other behavior that they already perform consistently in order to increase the consistency with which they enact a chosen value/characteristic.

Learning activity: Students first identify behavior that they believe they perform consistently and offer an explanation for why this is so. Then, students attempt to transfer their awareness of what makes them consistent at enacting the given behavior to the consistent expression of the chosen values/characteristics. Finally, students apply their experiential knowledge and motivation toward improving the enactment of their chosen values/characteristics during the week.

The group facilitator begins by asking students why they believe they are or are not consistent at performing some behavior in general and in certain situations. Students are encouraged to brainstorm strategies for expressing behavior more consistently, including how to compensate for any personal limitations or environmental barriers to consistent performance. Because intrinsic motivation is more likely to increase when opportunities exist to generate and apply authentic solutions to challenges (Burton, Lydon, D'Alessandro, \& Koestner, 2006; Levesque \& Brown 2007; Levesque, Copeland, \& Sutcliffe, 2008), the group facilitator refrains from introducing feedback on the strategies that students generate. This learning activity proceeds under the assumption that, if given the chance, human beings have the capacity and desire to assume responsibility for their personal growth (Burton et al., 2006; Fox \& Riconscente, 2008; Pintrich \& de Groot, 1990; Wolbert et al., 2015). From an evolutionary psychology perspective, well-being is the result of being able to seek or create conditions that improve the quality of life, and it reflects the adaptive neurocognitive capacities of human beings (Buss, 2000). Oddly enough, the evolutionary perspective comports with humanistic psychology and SDT on the role 
of freedom and agency in the decision to pursue goals that have personal meaning and value. Freedom and agency mean that individuals are autonomous and able to identify and strive for personalized goals that represent their experience of genetically unique needs for well-being and personal growth. Only through freedom and agency can individuals respond authentically to the evolutionary imperatives of survival, reproductive success, and psychological development. As Seligman and Csikszentmihalyi (2000) put it, when bridging positive psychology and evolutionary psychology, "individuals are the authors of their own evolution" (p. 9).

For example, a student whose chosen value/characteristic was "hardworking" stated, "I could not concentrate much on doing homework and reading books but could play computer games for many hours without getting bored; I believe I have the ability to concentrate, so I promised myself I would try to concentrate on my homework and textbook." This excerpt reveals how the student consciously contrasts and then synthesizes consistent with inconsistent behavior, culminating in a commitment to apply the skills associated with one behavior to the goal of enacting a chosen value/characteristic more consistently. To paraphrase Roeser and Peck (2009), the cultivation of conscious awareness transforms internal conflict into new personal growth through the discovery of the difference between the " $\mathrm{Me}^{\text {" (i.e., }}$ observed self) and the "I" (i.e., active self).

Another student whose chosen value/characteristic was "being respectful" observed that, while respectful to classmates at school, he fights with his older brother at home. He then synthesized consistent within consistent expressions of the chosen value/characteristic and recognized that he could to apply this synthesis to make interactions with his brother more consistent with his chosen value/characteristic: "We need to be respectful and not fight each other at home." This process of comparison followed by synthesis raises awareness and intrinsic motivation to operate with greater consistency in the enactment of desired values/characteristics across situations (Levesque \& Brown, 2007; Levesque et al., 2008; Pintrich \& de Groot, 1990) and emotional reactions (Ugur, Tanrikulu, \& Tosun, 2015). It may also enhance well-being, as in the case of a student who recounted, "I am happy now. I learned about my strengths, like being hardworking. I can compensate for my weaknesses."

In working with a student who always claims to express a chosen value/characteristic in situations that call for it, the group facilitator might ask the student to identify a prototype who best embodies the chosen value/characteristic and compare his or her own degree of consistency in expressing the value/characteristic with that of the prototype. Such a contrast will likely foster recognition of the gap between actual and aspired enactment of the chosen value/characteristic and heighten motivation to close that gap.

\section{Evaluation}

Learning goal: The goal for this level is to review the group-based curriculum and its learning goals, learning activities, and learning outcomes. Students are invited to 
reflect on how helpful their experiences were in raising self-awareness and in facilitating well-being and personal growth.

Learning activity: At the last group session, each student personally reviews the curriculum. Students recall the learning goals and activities of each level as well as the nature of their participation, the emotions they experienced, and the degree to which they believe the curriculum served to increase the consistent expression of the chosen values/characteristics in the context of their everyday lives. The group facilitators in our study observed that, as students progressed through the six levels, they focused more on their strengths than on their weaknesses. Students reported that they believed they could overcome their limitations by maintaining awareness and motivation to enact their chosen values/characteristics. One student summed it up thusly: "I do not need to be shy about expressing my weaknesses and strengths. The important thing is to develop my strengths and compensate for my weaknesses. I have already started to do this." Another student stated, "There were good activities. I told my parents every week. They also motivated me to improve. I believe I will be better at home and in class." This comment further suggests that parental support can enhance the motivation of students to pursue their chosen values/characteristics via consistent action (Inzlicht, Bartholow, \& Hirsh, 2015; Régner, Loose, \& Dumas, 2009).

Finally, most students also praised the supportive and encouraging atmosphere of the group. They expressed an interest in enrolling in another group in order to "work on" a second chosen value/characteristic.

\section{Conclusion}

We began this article with a description of the theoretical propositions drawn from humanistic psychology, positive psychology, self-determination mini-theories (particularly organismic integration theory and goal contents theory), and mindfulness, all theories that undergird a group-based curriculum developed at Fatih University in Istanbul and intended to enhance self-awareness, intrinsic motivation, eudaimonic well-being, and personal growth. We then presented the curriculum, which is structured according to the learning goals and activities of the six levels in the cognitive domain of Bloom's Taxonomy, with an infusion of elements from the taxonomy's affective domain. We believe that the learning goals and activities of the curriculum have promise for yielding psychological benefits for students. Students are guided through a sequence of cognitive and affective selfdevelopment learning activities, with each activity building upon the outcomes of the preceding ones, and are accompanied by the support and encouragement of peers and group facilitators. Combined with the anecdotal reactions of group members and facilitators, our impressions suggest that the consistent expression of personally selected values and characteristics requires that these aspects first become internalized as meaningful guides for living then motivate behavior (Shoda et al., 2015) that is consistent with the chosen values and characteristics, and ultimately contribute to a sense of well-being and personal growth. This progression is in line 
with the emphasis of Bloom's Taxonomy on cognitive and affective integration, the notion from SDT of values being integrated into the self (Bloom, 1956; Bloom et al., 1956; Krathwohl, 2002; Ryan et al., 2008), goal-content theory (e.g. Stevens et al., 2011; Stevens et al., 2015), mindfulness (Brown et al., 2007), and positive education (i.e., teaching, building, and embedding social and emotional learning throughout a student's experience; White \& Murray, 2015), all of which have beneficial effects on motivation, well-being, and educational performance. Although we have not subjected our group-based curriculum to rigorous empirical evaluation, we encourage efforts to establish its efficacy and effectiveness through qualitative and quantitative research (see White \& Murray, 2015). Our application procedure is outlined in detail and has solid theoretical and empirical foundations, so we suggest that future research could easily draw empirical assumptions from them and test them in a rigorous scientific way. For example, the efficacy of the application could be easily tested by conducting the procedure together with a placebo group and having pre and post measurements of both educational and psychological outcomes (e.g., well-being). Qualitative interviews and action research could also be used to investigate qualitatively and in depth the complexity of the proposed students' improvement, both educationally and psychologically

\section{References}

Allen, K., \& Friedman, B. (2010). Affective learning: A taxonomy for teaching social work values. Journal of Social Work Values E Ethics, 7(2). Retrieved August 5, 2013, from http://www.socialworker.com/jswve/fall2010/f10neuman.pdf

Alloy, L. B., \& Abramson, L. Y. (1979). Judgment of contingency in depressed and nondepressed students: Sadder but wiser? Journal of Experimental Psychology: General, 108, 441-485. doi:10.1037/0096-3445.108.4.441

Bandura, A. (1997). Self-efficacy: The exercise of control. New York, NY: Freeman.

Bauer, J. J., \& McAdams, D. P. (2004). Growth goals, maturity, and well-being. Developmental Psychology, 40, 114-127. doi:10.1037/0012-1649.40.1.114

Bauer, J. J., Park, S. W., Montoya, R. M., \& Wayment, H. A. (2015). Growth motivation toward two paths of eudaimonic self-development. Journal of Happiness Studies, 16, 185-210. doi:10.1007/s10902-014-9504-9

Baumeister, R. F., Campbell, J. D., Krueger, J. I., \& Vohs, K. D. (2003). Does high selfesteem cause better performance, interpersonal success, happiness, or healthier lifestyles? Psychological Science in the Public Interest, 4, 1-44. doi:10.1111/1529-1006.01431

Berndt, T. J. (1999). Friends' influence on students' adjustment to school. Educational Psychologist, 34, 15-28. doi:10.1207/s15326985ep3401_2 
Bloom, B. S. (1956). Taxonomy of educational objectives, Handbook I: The cognitive domain. New York, NY: David McKay.

Bloom, B. S., Engelhart, M. D., Furst, E. J., Hill, W. H., \& Krathwohl, D. R. (1956). Taxonomy of educational objectives: The classification of educational goals. Handbook I: Cognitive domain. New York, NY: David McKay.

Brown, K. W., Ryan, R. M., \& Creswell, J. D. (2007). Mindfulness: Theoretical foundation and evidence for its salutary effects. Psychological Inquiry, 18, 211237. doi: $10.1080 / 10478400701598298$

Burton, K. D., Lydon, J. E., D'Alessandro, D. U., \& Koestner, R. (2006). The differential effects of intrinsic and identified motivation on well-being and performance: Prospective, experimental, and implicit approaches to selfdetermination theory. Journal of Personality \& Social Psychology, 91, 750-762. doi:10.1037/0022-3514.91.4.750

Buss, D. M. (2000). The evolution of happiness. American Psychologist, 55, 15-23. doi:10.1037/0003-066X.55.1.15

Deci, E. L., \& Ryan, R. M. (2000). The 'what' and 'why' of goal pursuits: Human needs and the self-determination of behavior. Psychological Inquiry, 11, 227-268. doi:10.1207/S15327965PLI1104_01

Fox, E., \& Riconscente, M. (2008). Metacognition and self-regulation in James, Piaget, and Vygotsky. Educational Psychology Review, 20, 373-389.doi:10.1007/s10648008-9079-2

Frankl, V. E. (1969). Man's search for meaning: An introduction to logotherapy. London, UK: Hodder \& Stoughton.

Frost, K. M., \& Frost, C. J. (2000). Romanian and American life aspirations in relation to psychological well-being. Journal of Cross-Cultural Psychology, 31, 726-751. doi:10.1177/0022022100031006004

Inzlicht, M., Bartholow. B. D., \& Hirsh, J. B. (2015). Opinion: Emotional foundations of cognitive control. Trends in Cognitive Sciences, 19, 26-132. doi:10.1016/j.tics.2015.01.004

Jahoda, M. (1953). The meaning of psychological health. Social Casework, 34, 349-354.

Kasser, T., \& Ryan, R. M. (1993). A dark side of the American dream: Correlates of financial success as a central life aspiration. Journal of Personality $\mathcal{E}$ Social Psychology, 65, 410-422. doi:10.1037/0022-3514.65.2.410

Kiaci, Y. A., \& Reico, T. G., Jr. (2014). Goal pursuit and eudaimonic well-being among university students: Metacognition as the mediator. Behavioral Development Bulletin, 19(4), 91-104. doi:10.1037/h0101085 
Kidder, R. M. (1994a). Shared values for a troubled world: Conversations with men and women of conscience. San Francisco, CA: Jossey-Bass.

Kidder, R. M. (1994b). Universal human values. Futurist, 28(4), 8-13.

Kinnier, R. T., Kernes, J. L., \& Dautheribes, T. M. (2000). A short list of universal moral values. Counseling $\mathcal{E}$ Values, 45, 4-17. doi:10.1002/j.2161007X.2000.tb00178.x

Krathwohl, D. R. (2002). A revision of Bloom's Taxonomy: An overview. Theory into Practice, 41, 212-264. doi:10.1207/s15430421tip4104_2

Krathwohl, D. R., \& Anderson, W. L. (2010). Merlin C. Wittrock and the revision of Bloom's Taxonomy. Educational Psychologist, 45,64-65. doi:10.1080/00461520903433562

Levesque, C., \& Brown, K. W. (2007). Mindfulness as a moderator of the effect of implicit motivational self-concept on day-to-day behavioral motivation. Motivation E Emotion, 31, 284-299. doi:10.1007/s11031-007-9075-8

Levesque, C., Copeland, K. J., \& Sutcliffe, R. A. (2008). Conscious and nonconscious processes: Implications for self-determination theory. Canadian Psychology, 49, 218-224. doi:10.1037/a0012756

Maslow, A. H. (1950). Self-actualizing people: A study of psychological health. PersonalitySymposium, 1, 11-34.

Maslow, A. H. (1968). Toward a psychology of being (2nd ed.). New York, NY: Van Nostrand.

Newman, R. S. (2000). Social influences on the development of children's adaptive help seeking: The role of parents, teachers, and peers. Developmental Review, 20, 350-404. doi:10.1006/drev.1999.0502

Pintrich, P. R., \& de Groot, E. V. (1990). Motivational and self-regulated learning components of classroom academic performance. Journal of Educational Psychology, 82, 33-40. doi:10.1037/0022-0663.82.1.33

Régner, I., Loose, F., \& Dumas, F. (2009). Students' perceptions of parental and teacher academic involvement: Consequences on achievement goals. European Journal of Psychology of Education, 24, 263-277. doi:10.1007/BF03173016d

Robins, R. W., \& Beer, J. S. (2001). Positive illusions about the self: Short-term benefits and long-term costs. Journal of Personality \& Social Psychology, 80, 340-352. doi:10.1037/0022-3514.80.2.340

Roeser, R. W., \& Peck, S. C. (2009). An education in awareness: Self, motivation, and self-regulated learning in contemplative perspective. Educational Psychologist, 44, 119-136. doi:10.1080/00461520902832376 
Rogers, C. R. (1961). On becoming a person: A therapist's view of psychotherapy. London, UK: Constable.

Rogers, C. R. (1964). Toward a modern approach to values: The valuing process in the mature person. Journal of Abnormal \& Social Psychology, 68, 160-167. doi:10.1037/h0046419

Ryan, A. M. (2000). Peer groups as a context for the socialization of adolescents' motivation, engagement, and achievement in school. Educational Psychologist, 35, 101-111. doi:10.1207/S15326985EP3502_4

Ryan, R. M., Chirkov, V. I., Little, T. D., Sheldon, K. M., Timoshina, E., \& Deci, E. L. (1999). The American dream in Russia: Extrinsic aspirations and well-being in two cultures. Personality \& Social Psychology Bulletin, 25, 1509-1524. doi:10.1177/01461672992510007

Ryan, R. M., \& Deci, E. L. (2000). The darker and brighter sides of human existence: Basic psychological needs as a unifying concept. Psychological Inquiry, 11, 319338. doi:10.1207/S15327965PLI1104_03

Ryan, R. M., \& Deci, E. L. (2001). On happiness and human potentials: A review of research on hedonic and eudaimonic well-being. In S. Fiske (Ed.), Annual review of psychology (Vol. 52, pp. 141-166). Palo Alto, CA: Annual Reviews.

Ryan, R. M., Huta, V., \& Deci, E. L. (2008). Living well: A self-determination theory perspective on eudaimonia. Journal of Happiness Studies, 9, 139-170. doi:10.1007/s10902-006-9023-4

Schmuck, P., Kasser, T., \& Ryan, R. M. (2000). The relationship of well-being to intrinsic and extrinsic goals in Germany and the U.S. Social Indicators Research, 50, 225-241. doi:10.1023/ A:1007084005278

Schneider, K. (2011). Toward a humanistic positive psychology: Why can't we just get along. Journal of the Society for Existential Analysis, 22, 32-38.

Schueller, S. M., \& Seligman, M. E. (2010). Pursuit of pleasure, engagement, and meaning: Relationships to subjective and objective measures of well-being. Journal of Positive Psychology, 5, 253-263. doi:10.1080/17439761003794130

Schunk, D. H. (1999). Social-self interaction and achievement behavior. Educational Psychologist, 34, 219-227. doi:10.1207/s15326985ep3404_3

Schwartz, S. H. (2006). Les valeurs de base de la personne: Théorie, mesures et applications [Basic human values: Theory, measurement, and applications]. Revue Francaise deSociologie, 42, 249-288.

Seligman, M. E. P. (2007). Coaching and positive psychology. Australian Psychologist, 42, 266-267. doi:10.1080/00050060701648233 
Seligman, M. E. P., \& Csikszentmihalyi, M. (2000). Positive psychology: An introduction. American Psychologist, 55, 5-14. doi:10.1037/0003-066X.55.1.5

Sheldon, K., Joiner, T., Pettit, J., \& Williams, G. (2003). Reconciling humanistic ideals and scientific clinical practice. Clinical Psychology: Science \& Practice, 10, 302315. doi:10.1093/clipsy.bpg026

Shoda, Y., Wilson, N. L., Whitsett, D. D., Lee-Dussud, J., \& Zayas, V. (2015). The person as a cognitive-affective processing system: Quantitative ideography as an integral component of cumulative science. In M. Mikulincer, P. R. Shaver, M. L. Cooper, \& R. J. Larsen (Eds.), APA handbook of personality and social psychology, Volume 4: Personality processes and individual differences (pp. 491513). Washington, DC: American Psychological Association.

Stevens, M. J., Constantinescu, P-M., \& Butucescu, A. (2011). Aspirations and wellbeing in Romanian and U.S. undergraduates. International Journal of Psychology, 46, 436-445. doi:10.1080/00207594.2011.565344

Stevens, M. J., Constantinescu, P-M., Ugur, H., \& Constantinescu, I. (2015). Causality orientations and psychological well-being in young European and Eurasian adults. International Perspectives in Psychology: Research, Practice, Consultation, 4, 37-50. doi:10.1037/ipp0000028

Taylor, S. E., \& Brown, J. D. (1988). Illusion and well-being: A social psychological perspective on mental health. Psychological Bulletin, 103, 93-210. doi:10.1037/0033-2909.103.2.193

Tuominen-Soini, H., Salmela-Aro, K., \& Niemivirta, M. (2008). Achievement goalorientations and subjective well-being: A person-centered analysis. Learning EInstruction, 18, 251-266. doi:10.1016/j.learninstruc.2007.05.003

Ugur, H., Tanrikulu, T., \& Tosun, U. (2015). Personal awareness and emotional reactions: A study of content analysis. The Journal of Academic Social Science Studies, 34(2), 237-248. doi:10.9761/JASSS2846

Vansteenkiste, M., Lens, W., \& Deci, E. L. (2006). Intrinsic versus extrinsic goal contents in self-determination theory: Another look at the quality of academic motivation. Educational Psychologist, 41, 19-31. doi:10.1207/s15326985ep4101_4

Vansteenkiste, M., Niemiec, C. P., \& Soenens, B. (2010). The development of the five mini-theories of self-determination theory: An historical overview, emerging trends, and future directions. In T. C. Urdan \& S. A. Karabenick (Eds.), Advances in motivation and achievement: The decade ahead. Theoretical perspectives on motivation and achievement (Vol. 16A, pp. 105-165). London, UK: Emerald Group Publishing.

Waterman, A. S. (2008). Reconsidering happiness: A eudaimonist's perspective. Journal of Positive Psychology, 3, 234-252. doi:10.1080/17439760802303002 
Wentzel, K. R., \& Wigfield, A. (2007). Motivational interventions that work: Themes and remaining issues. Educational Psychologist, 42, 261-271. doi:10.1080/00461520701621103

White, M. A., \& Murray, A. S. (Eds.). (2015). Evidence-based approaches in positive education: Implementing a strategic framework for well-being in schools. New York, NY: Springer Science + Business Media. doi:10.1007/978-94-017-9667-5

Williams, W. M., \& Blythe, T. (2002). Practical intelligence for school: Developing metacognitive sources of achievement in adolescence. Developmental Review, 22, 162-210. doi: 10.1006/drev.2002.0544

Wolbert, L. S., de Ruyter, D. J., \& Schinkel, A. (2015). Formal criteria for the concept of human flourishing: The first step in defending flourishing as an ideal aim of education. Ethics and Education, 10, 188-129. doi:10.1080/17449642.2014.998032

Wolters, C. A. (2003). Regulation of motivation: Evaluating an underemphasized aspect of self-regulated learning. Educational Psychologist, 38, 189-205. doi:10.1207/S15326985EP38041 